\title{
Failed surgical ligation of the proximal left subclavian artery during hybrid thoracic endovascular aortic repair successfully managed by percutaneous plug or coil occlusion: a report of 3 cases
}

\author{
Geert Maleux*, Johan Vaninbroukx and Sam Heye
}

\begin{abstract}
Open surgical rerouting and proximal ligation of one or more supra-aortic vessels prior to endovascular stent-graft placement has become an alternative to major open thoracic surgery in the treatment of complex thoracic aortic disease. Complications owing to failed surgical ligation of the left subclavian artery are rare. In this report, 3 cases of failed ligation are presented. Diagnosis was made by $\mathrm{CT}$-scan and treatment was performed by transcatheter coil and plug embolization, avoiding redo neck surgery.
\end{abstract}

\section{Background}

Endovascular repair has become a valuable alternative to open repair for the treatment of several thoracic aortic pathologies [1-4]. However, stent-graft placement requires an adequate proximal and distal landing zone in the aorta of at least $2 \mathrm{~cm}$ in order to avoid early or late type I endoleak. Therefore, surgical ligation and rerouting of one or more supra-aortic vessels can be necessary for safe stent-graft deployment and efficient and durable clinical outcome. Recent reports deal with the successful technical and clinical outcome after supra-aortic rerouting [5-7]. However, type and management of complications related to this type of open vascular surgery are scarce and not well-documented [7]. In this report we present the clinical and radiological outcome after endovascular management of failed surgical ligation of the left subclavian artery during supraaortic rerouting for safe thoracic stent-graft placement.

From 1999 to end of 2009, 172 thoracic stent-graft procedures in 160 patients were performed in the author's institution. In 49 patients (30\%), supra-aortic rerouting was performed. In 41 out of these 49 patients (84\%) perioperative surgical ligation of the left

* Correspondence: geert.maleux@uzleuven.be

Department of Radiology, University Hospitals Leuven, Belgium subclavian artery was performed in association with supra-aortic rerouting. All patients were followed up according to the EUROSTAR guidelines [8]. In 3 out of these 41 patients $(7 \%)$ previously treated by left subclavian artery ligation, persistent flow through the ligated artery was identified and associated with gradual increase of aneurismal or false luminal diameter. There were no patients with persistent retrograde flow through the prevertebral left subclavian artery, but with a stable or decreasing aneurismal sac.

\section{Case Presentation}

\section{Case 1}

A 65-year-old man presented with persistent thoracic pain since two weeks. Serial computed tomography (CT) scans revealed an aortic dissection, Stanford type II starting at the origin of the left subclavian artery (Figure 1) and with progressive increase of thoracic aortic diameter up to $5 \mathrm{~cm}$ over a two week time period. A decision was taken to exclude the aneurismal false lumen with use of a stent-graft (Talent, Medtronic, Santa Rosa, CA, USA). Because of unintentional covering of the origin of the left common carotid artery, a carotidocarotid bypass was performed, but despite many intraoperative efforts, it was not possible to ligate the proximal left 


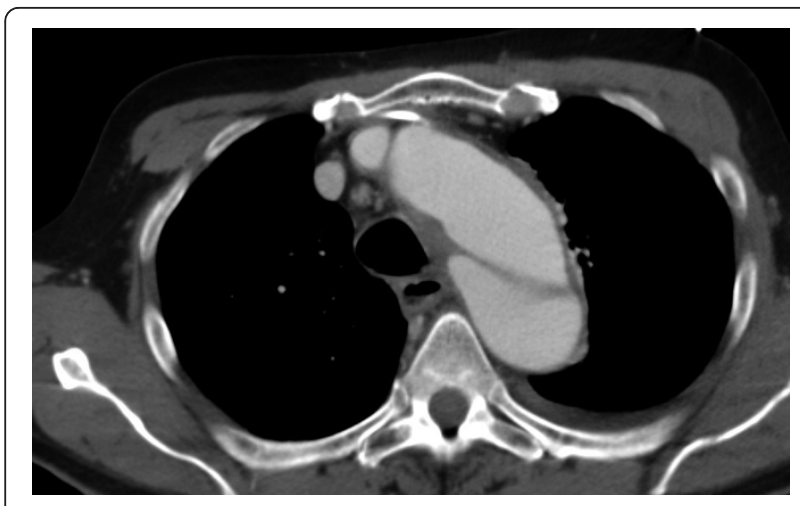

Figure 1 Thoracic aortic CT-scan at admission reveals a classic Stanford type B aortic dissection without clear false lumen dilatation.

subclavian artery via the cervicotomy. The patient recovered well without neurological sequellae and the thoracic pain disappeared progressively. Control physical examination at 3, 6 and 12 months after the thoracic endovascular aortic repair (TEVAR) was uneventful except for a persistent left radial pulse. CT-scans revealed a persistent opacification of the false lumen and the entire left subclavian artery (Figure 2). A discrete increase in thoracic aortic diameter up to $59 \mathrm{~mm}$ was noted. Catheter angiography performed 13 months after initial EVAR showed a fully patent stent-graft and retrograde opacification of the false lumen through connections between true and false aortic lumen at the level

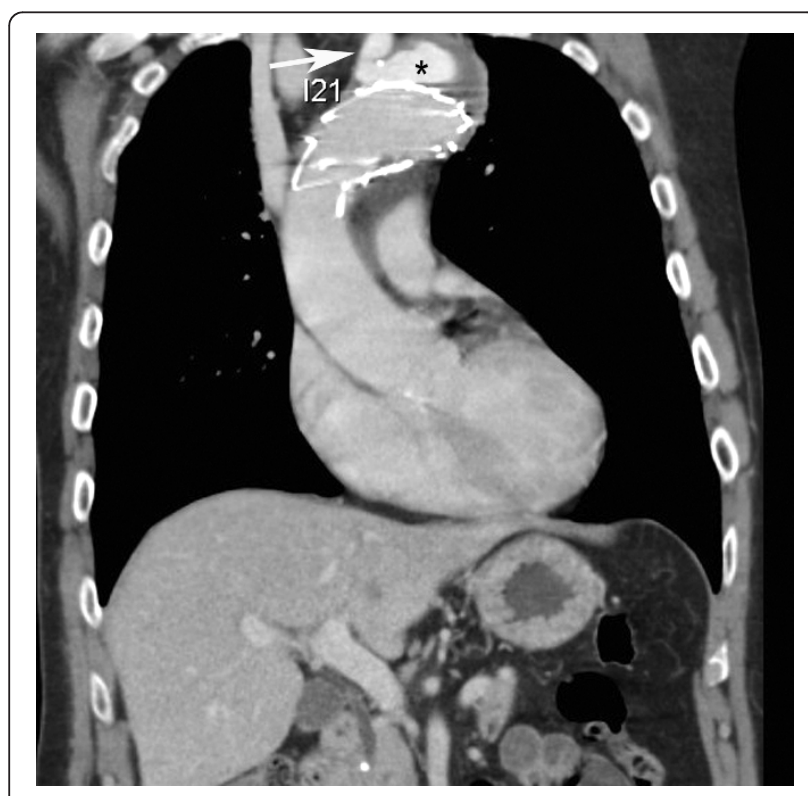

Figure 2 Coronal CT-reconstruction image one year after stentgrafting shows persistent opacification of both the left subclavian artery (white arrow) and the false thoracic aortic lumen (black asterisk). of the thoraco-abdominal and abdominal aorta; no subclavian steal phenomenon was identified (Figure 3a-b). After puncturing the left brachial artery and cannulation of the proximal subclavian artery and false lumen, selective angiography revealed antegrade opacification of the left subclavian and vertebral artery: the left upper limb and left posterior circulation was feeded antegradely via the retrogradely perfused false aortic lumen. It was decided to occlude the prevertebral segment of the left subclavian artery using a $16 \mathrm{~mm}$ diameter vascular plug (Amplatzer plug, AGA Medical, Plymouth, MN, USA). Completion angiography after plug placement revealed a suclavian steal via retrograde opacification of the left vertebral artery and antegrade opacification of the subclavian artery with exception of the completely thrombosed prevertebral segment (Figure 4a-b). Clinically, there was no more radial pulse palpable and symptoms of left arm claudication were noted, but these were managed conservatively.

Control CT-scan one year later showed a progressive increase in diameter of the distal thoracic aorta below the stent-graft. An extension stent-graft (Talent, Medtronic, USA) was successfully placed landing at the tenth thoracic vertebra. The patient was discharged 3 days later. CT-scan at 1,2 and 3 years follow-up after placement of the extention stent-graft revealed complete thrombosis of the false lumen and occlusion of the left subclavian artery with the occlusion-plug in place. The diameter of the thoracic aorta remained stable with a maximum diameter of $50 \mathrm{~mm}$ (Figure 5).

\section{Case 2}

A 78-year-old man presented with an asymptomatic aneurysm of the proximal descending thoracic aorta with a maximal diameter of $66 \mathrm{~mm}$. The patient already underwent endovascular exclusion of an abdominal aortic aneurysm two years earlier. It was decided to exclude the thoracic aneurysm with use of a stent-graft (Valiant, Medtronic, Santa Clara, CA, USA) after placing a carotidosubclavian bypass and ligation of the proximal left subclavian artery in order to minimize potential postoperative neurological symptoms related to myelum ischemia. The postoperative period was uneventful except for fever up to $38^{\circ} \mathrm{C}$ for 3 days; no signs of arm claudication were noted. Control CT-scan 6 months later revealed discrete increase of the aneurismal sac diameter up to $69 \mathrm{~mm}$ owing to a type II endoleak by retrograde sac perfusion through the incompletely ligated proximal left subclavian artery. It was decided to treat the endoleak. Under local anesthesia, the left brachial artery was punctured and a $45 \mathrm{~cm}$ long $8 \mathrm{~F}$ sheath (Arrows, Reading, PE, USA) was inserted. Angiography revealed the retrograde opacification of the prevertebral segment of the left subclavian artery, resulting in a type 


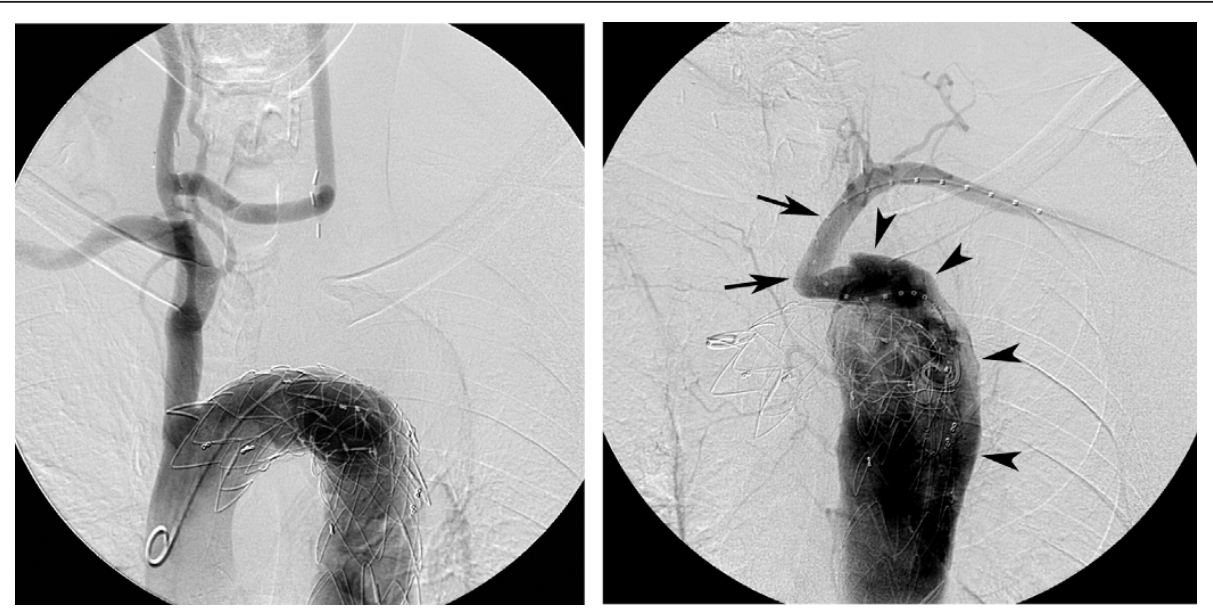

Figure 3 Catheter angiography of the aortic arch. (a) Catheter angiography of the aortic arch, 13 months after hybrid surgery shows the stent-graft in place, starting just distal to the origin of the brachiocephalic trunk. Note also the good patency of the carotido-carotid bypass. There is no opacification of the left subclavian artery. (b) After puncturing the left brachial artery, a calibrated pigtail is navigated through the proximal left subclavian artery (arrows) into the false lumen of the thoracic aorta (arrowheads). Note the antegrade flow in the left subclavian artery.

II endoleak. A $16 \mathrm{~mm}$ nominal diameter vascular plug (Amplatzer vascular plug, AGA Medical, Plymouth, MN, USA) was placed at the origin of the left subclavian artery, with complete disappearence of the endoleak. Control CT-scan at one and two years follow-up revealed absence of any residual type II endoleak and stable diameter of the thoracic aneurysm up to $68 \mathrm{~mm}$.

\section{Case 3}

A 68-year-old man presented with an asymptomatic, focal atherosclerotic aneurysm of the aortic arch (maximal diameter of $6 \mathrm{~cm}$ ) and another, focal, thoracoabdominal aneurysm with a diameter of $5.5 \mathrm{~cm}$, ending at the level of the origin of the renal arteries. Eleven years ago, the patient also underwent an elective surgical repair for an infrarenal abdominal aortic aneurysm. It was decided to first treat the arch aneurysm with use of a hybrid vascular procedure: A carotid-carotid bypass with additional bypass to the left subclavian artery was performed using a Silver $8 \mathrm{~mm}$ vascular graft; concomitantly a surgical ligation of the left subclavian artery proximal to the origin of the left vertebral artery was performed. Afterwards a stent-graft (TAG, W.L. Gore \& Associates, Flagstaff, AZ, USA) starting at the origin of the brachiocephalic trunk and ending in the descending thoracic aorta, was inserted and resulting in a complete

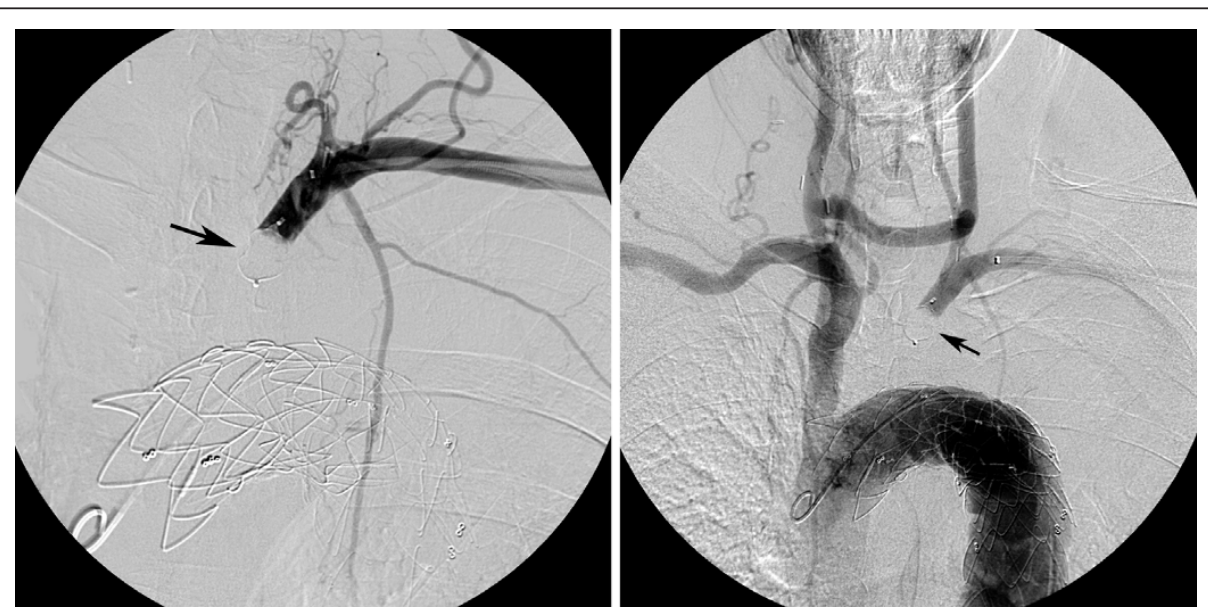

Figure 4 Angiography after Amplatzer-plug deployment. (a) Selective injection of contrast medium in the distal left subclavian artery after Amplatzer-plug deployment (arrow) demonstrates a total occlusion of the proximal left subclavian artery. (b) Flush aortography after Amplatzerplug deployment (arrows) reveals retrograde opacification (subclavian steal phenomenon) of the left subclavian artery through the retrogradely filling left vertebral artery. 


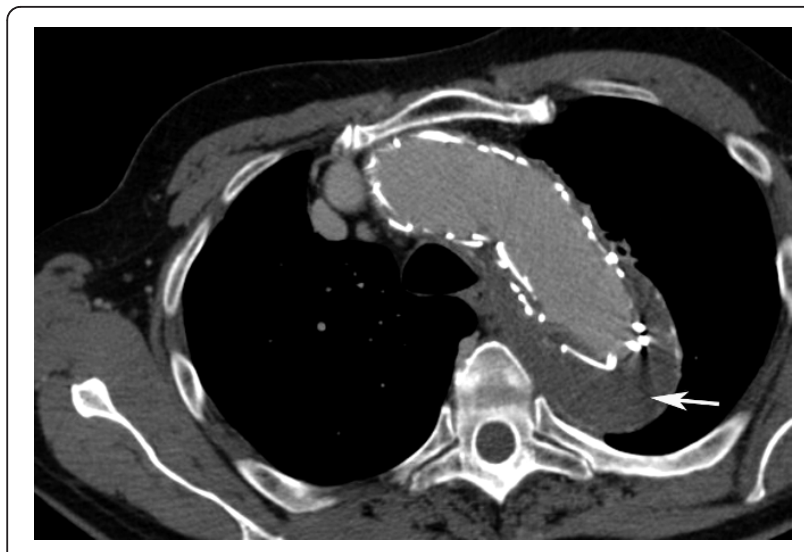

Figure 5 Control CT-scan 3 years after stent-graft extension shows a stable thoracic aortic diameter of $50 \mathrm{~mm}$ without contrast opacification of the excluded false lumen, both in the early arterial and in the late venous phase.

exclusion of the aneurysm. Postoperative follow-up was uneventful and three months later, patient underwent a Crawford operation for his thoraco-abdominal aneurysm with reimplantation of all visceral arteries including celiac trunk, superior mesenteric artery and both renal arteries. Six months later, follow-up CT-scan revealed a growing thoracic arch aneurysm and a type II endoleak by retrograde perfusion of the aneurysmal sac through an incompletely ligated left subclavian artery (Figure 6). It was decided to treat the type II endoleak by transcatheter technique. After local anesthesia, the left

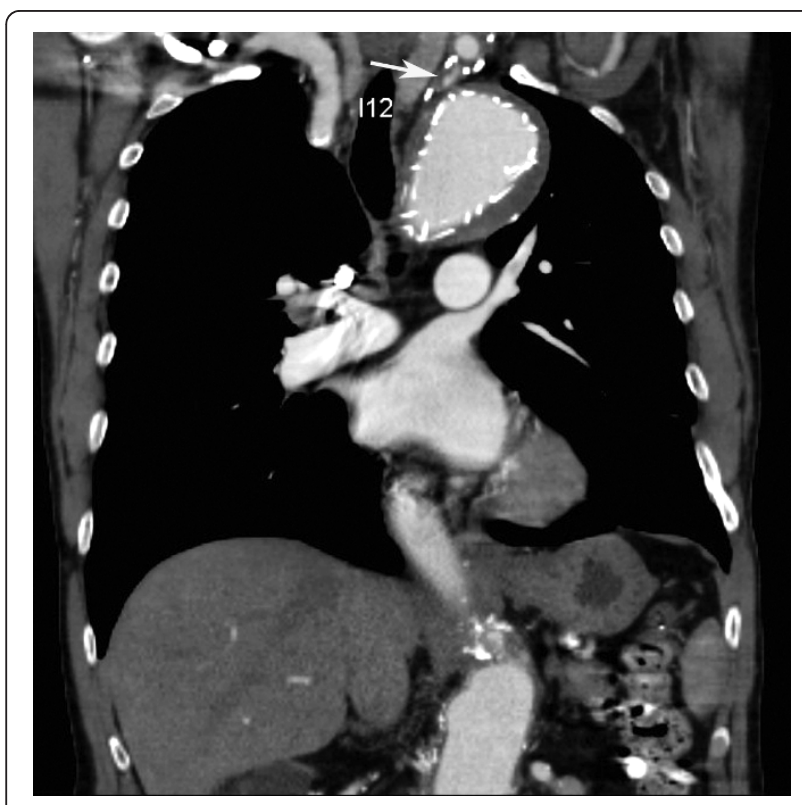

Figure 6 Coronal CT-reconstruction image 6 months after stent-grafting reveals a faint opacification (white arrow) of the proximal left subclavian artery with focal opacification of the aneurismal sac lumen. brachial artery was punctured and a 4F sheath was introduced. Through a 4F Cobra-catheter (Cook Medical, Bloomington IN, USA) a microcatheter (Miraflex, Cook Medical, Bloomington IN, USA) was navigated with the tip in the proximal left subclavian artery. Deployment of 3 fibered microcoils (Target Therapeutics, Boston Scientific Corporation, Natick, MA, USA) completely occluded the origin of the left subclavian artery with disappearance of the endoleak (Figure 7a-b). Control CT-scan 9 months later revealed a completely excluded thoracic aortic aneurysm without endoleak and stable in diameter.

\section{Discussion}

Combined open and endovascular surgical repair is recently propagated as a less invasive treatment option for the management of aortic arch pathologies like aneurysms, dissections or penetrating ulcers [1,7,9-12]. However, these operations are also not free of early or late complications: myocardial infarction, respiratory and renal failure, postoperative hematoma, vertebrobasilar insufficiency or stroke are potential complications [13-18]. In this study we report on a yet unreported, not very uncommon (7\% of all supraaortic rerouting cases with ligation), but silent complication after supra-aortic rerouting, namely an incomplete ligation of the left subclavian artery resulting in persistent perfusion of the thoracic aneurysm in two cases and in persistent, retrograde perfusion of the false lumen in the remaining case. Additionally, in all cases these radiological findings were associated with a gradual growth of the aneurismal sac or false lumen, stressing the importance of this silent complication. Adequate treatment seems to be mandatory to avoid potential late rupture. In the presented cases, a surgical attempt was made to ligate the prevertebral segment of the left subclavian artery; however, owing to surgical difficulties to clearly visualize and manipulate the deeply located proximal left subclavian artery, the ligation was incomplete in two cases and impossible in the remaining case. It is also understandable that a redo operation in these cases is even more hazardous and by consequence, a minimally invasive alternative treatment is preferred. Persistent flow through the left subclavian artery was identified in all three cases by contrast-enhanced CT-scan, underlining the value of regular follow-up CT-scan after endovascular repair of aortic pathologies. In all three cases the proximal left subclavian artery was approached by puncture of the left brachial artery; the decision to occlude with coils [19-21] or plug [13,22-25] depended on the diameter of the prevertebral subclavian artery segment: if the segment was large enough for a plug $(n=2)$, then a plug was preferred owing to the ease of plug deployment; in the remaining case the prevertebral segment 


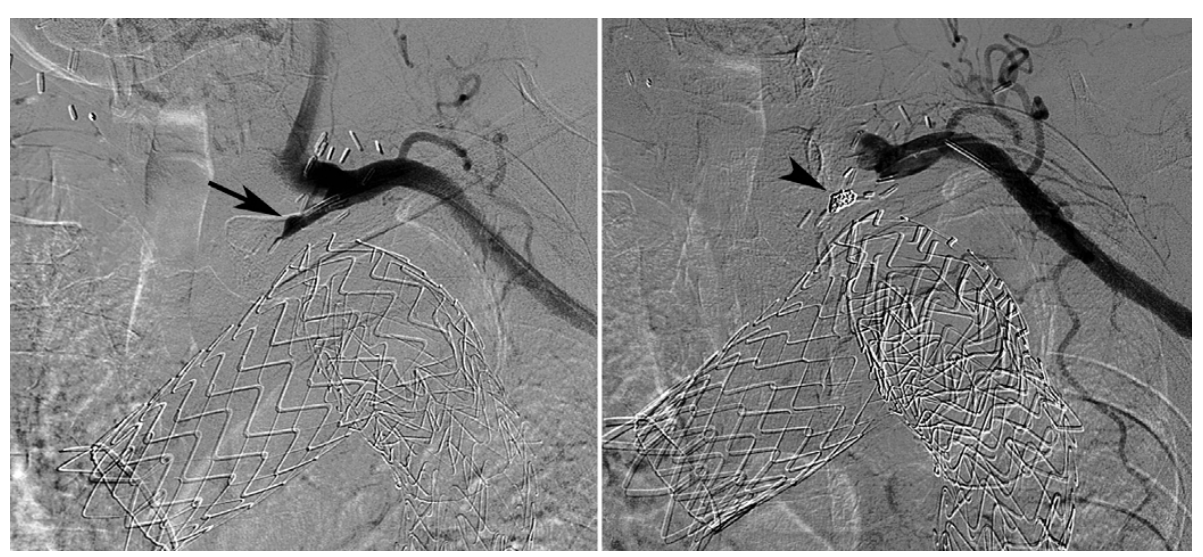

Figure 7 Catheter angiography of the left subclavian artery. (a) Selective injection of the left subclavian artery through a brachial artery catheter shows a well-functioning carotido-subclavian bypass and faint retrograde opacification of the proximal left subclavian artery and aneurismal sac (arrow), suggesting a type II endoleak. (b) After coil embolisation (arrowhead), there is no more opacification of both the proximal left subclavian artery and the small type II endoleak.

was too small for safe plug-deployment and microcoils were placed through a microcatheter. Except for a puncture site hematoma, no complications occurred during or after the procedure and in all cases no more perfusion of the occluded vessel was indentified on sequential follow-up CT-scan. The endovascular occlusion of the proximal left subclavian artery has been successfully performed in cases of intentional left subclavian artery coverage by the endograft, without previous carotidsubclavian transposition [13,19,20,22-25], using the same endovascular techniques. Finally, the gradual growth of the aneurismal sac or false lumen was stopped after the occlusion procedure.

\section{Conclusions}

In summary, three cases of persistent flow through the left subclavian artery after combined open en endovascular surgery for thoracic aortic disease are presented. CT-scan clearly identified the persistent left subclavian artery opacification, despite previous surgical attempt of ligation; catheter-angiography confirmed these findings. Definitive occlusion of the prevertebral part of the left subclavian artery can be performed using plug or coils, resulting in disappearance of the endoleak and in cessation of the aneurismal or false lumen growth.

\section{Consent}

In our institution no approval of the Ethical Committee is required for case reports.

\section{Authors' contributions}

GM has taken care of the concept, design and the acquisition of data. SH as well as JV have taken care of the acquisition of data, the revision of the manuscript, and the final approval for the manuscript to be published. All contributing authors have read and approved the final manuscript.

\section{Competing interests}

The authors declare that they have no competing interests.

Received: 17 December 2010 Accepted: 8 April 2011

Published: 8 April 2011

\section{References}

1. Gaxotte V, Thony F, Rousseau H, Lions C, Otal P, Willeteaux S, Rodiere M, Negaiwi Z, Joffre F, Beregi JP: Midterm results of aortic diameter outcomes after thoracic stent-graft implantation for aortic dissection: A multicenter study. J Endovasc Ther 2006, 13:127-138.

2. Garzon G, Fernandez-Velilla M, Marti M, Acitores I, Ybanez F, Riera L: Endovascular stent-graft treatment of thoracic aortic disease. Radiographics 2005, 25:229-244

3. Fernandez V, Mestres G, Maeso J, Domínguez JM, Aloy MC, Matas M: Endovascular treatment of traumatic thoracic aortic injuries: short- and medium-term follow-up. Ann Vasc Surg 2010, 24(2):160-166.

4. Rousseau H, Bolduc JP, Dambrin C, Marcheix B, Canevet G, Otal P: Stentgraft repair of thoracic aortic aneurysms. Tech Vasc Interv Radiol 2005, 8(1):61-72.

5. Gottardi R, Funovics M, Eggers N, Hirner A, Dorfmeister M, Holfeld J, Zimpfer D, Schoder M, Donas K, Weigang E, Lammer J, Grimm M, Czerny M: Supra-aortic transposition for combined vascular and endovascular repair of aortic arch pathology. Ann Thor Surg 2008, 86:1524-1529.

6. Czerny M, Gottardi R, Zimpfer D, Schoder M, Grabenwoger M, Lammer J, Wolner E, Grimm M: Mid-term results of supra-aortic transpositions for extended endovascular repair of aortic arch pathologies. Eur J Cardiothorac Surg 2007, 31:623-627.

7. Younes HK, Davies MG, Bismuth J, Naoum JJ, Peden EK, Reardon MJ, Lumsden AB: Hybrid thoracic endovascular aortic repair: pushing the envelope. J Vasc Surg 2010, 51(1):259-266.

8. Leurs LJ, Bell R, Degrieck Y, Thomas S, Hobo R, Lundbom J, EUROSTAR; UK Thoracic Endograft Registry collaborators: Endovascular treatment of thoracic aortic diseases: combined experience from the EUROSTAR and United Kingdom Thoracic Endograft registries. J Vasc Surg 2004, 40(4):670-679, discussion 679-680.

9. Kusagawa H, Shimonon T, Ishida M, Suzuki T, Yasuda F, Yuasa U, Onoda K, Yada I, Hirano T, Takeda K, Kato N: Changes in false lumen after transluminal stent-graft placement in aortic dissections: six years' experience. Circulation 2005, 111:2951-2957.

10. Schoder M, Czerny M, Cejna M, Rand T, Stadler A, Sodeck GH, Gottardi R, Loewe C, Lammer J: Endovascular repair of acute type B aortic dissection: long-term follow-up of true and false lumen diameter changes. Ann Thor Surg 2007, 83:1059-1066.

11. Lopera J, Patino JH, Urbina C, Garcia G, Alvarez LG, Upegui L, Jhanchai A, Qian Z, Castaneda-Zuniga W: Endovascular treatment of complicated 
type-B aortic dissection with stent-grafts: Midterm results. J Vasc Interv Radiol 2003, 14:195-203.

12. Czerny M, Zimpfer D, Rodler S, Funovics M, Dorfmeister M, Schoder M, Marta G, Weigang E, Gottardi R, Lammer J, Wolner E, Grimm M: Endovascular stent-graft placement of aneurysms involving the descending aorta originating from chronic type B dissections. Ann Thor Surg 2007, 83:1635-1639.

13. Chaudhuri A, Tibballs J, Nadkarni S, Garbowski M: Digital embolization due to partially uncovered left subclavian artery post Tevar: Management with Amplatzer vascular plug occlusion. J Endovasc Ther 2007, 14:1545-1550.

14. Peterson BG, Eskandari MK, Gleason TG, Morasch MD: Utility of left subclavian artery revascularisation in association with endoluminal repair of acute and chronic thoracic aortic pathology. J Vasc Surg 2006, 43:433-439.

15. Weigang E, Luehr M, Harloff A, Euringer W, Etz CD, Szabo G, Beyersdorf F, Siegenthaler MP: Incidence of neurological complications following overstenting of the left subclavian artery. Eur J CardioThor Surg 2007, 31:628-636.

16. Riesenman PJ, Farber MA, Mendes RR, Marston WA, Fulton JJ, Keagy BA: Coverage of the left subclavian artery during thoracic endovascular aortic repair. J Vasc Surg 2007, 45:90-95.

17. Rehders TC, Petzsch M, Ince H, Kische S, Kôrber T, Koschyk DH, Chatterjee T, Weber F, Nienaber CA: Intentional occlusion of the left subclavian artery during stent-graft implantation in the thoracic aorta: risk and relevance. $J$ Endovasc Ther 2004, 11:659-666.

18. Messé SR, Bavaria JE, Mullen M, Cheung AT, Davis R, Augoustides JG, Gutsche J, Woo EY, Szeto WY, Pochettino A, Woo YJ, Kasner SE, McGarvey M: Neurologic outcomes from high risk descending thoracic and thoracoabdominal aortic operations in the era of endovascular repair. Neurocrit Care 2008, 9(3):344-351.

19. Lacroix V, Astarci P, Devaux P, Goffette P, Hammer F, Verhelst R, Noirhomme P: Endovascular treatment of an aneurysmal aberrant right subclavian artery. J Endovasc Ther 2003, 10:190-194.

20. Peterson MD, Wheatley GH, Kpodonu J, Williams JP, Ramaiah VG, Rodriguez-Lopez JA, Dietrich EB: Treatment of type II endoleaks associated with left subclavian artery coverage during thoracic aortic stent grafting. J Thorac Cardiovasc Surg 2008, 136:1193-1199.

21. Rabellino M, Nielsen LG, Baldi S, Zander T, Arnaiz L, Llorens R, Zerolo I. Maynar M: Retrograde embolization of the left vertebral artery in a type II endoleak after endovascular treatment of aortic thoracic rupture: technical note. Cardiovasc Intervent Radiol 2009, 32:169-173.

22. Kato N, Semba CP, Dake MD: Use of a self-expanding vascular occluder for embolization during endovascular aortic aneurysm repair. J Vasc Interv Radiol 1997, 8:27-33.

23. Hoppe H, Hohenwalter EJ, Kaufman JA, Petersen B: Percutaneous treatment of aberrant right subclavian artery aneurysm with use of the Amplatzer septal occluder. J Vasc Interv Radiol 2006, 17:889-894.

24. Ferro C, Petrocelli F, Rossi UG, Bovio G, Dahmane M'H, Seitun S: Vascular percutaneous transcatheter embolization with a new device: Amplatzer vascular plug. Radiol Med 2007, 112:239-251.

25. Meyer C, Probst C, Strunk H, Schiller W, Wilhelm K: Second-generation Amplatzer vascular plug (AVP) for the treatment of subsequent subclavian backflow type II endoleak after TEVAR. CardioVasc Intervent Radiol 2009, 32:1264-1267.

doi:10.1186/1749-8090-6-45

Cite this article as: Maleux et al:: Failed surgical ligation of the proximal left subclavian artery during hybrid thoracic endovascular aortic repair successfully managed by percutaneous plug or coil occlusion: a report of 3 cases. Journal of Cardiothoracic Surgery 2011 6:45.

\section{Submit your next manuscript to BioMed Central and take full advantage of:}

- Convenient online submission

- Thorough peer review

- No space constraints or color figure charges

- Immediate publication on acceptance

- Inclusion in PubMed, CAS, Scopus and Google Scholar

- Research which is freely available for redistribution

Submit your manuscript at www.biomedcentral.com/submit
Ciomed Central 